\title{
Model comparison and sensitivity analysis for a fixed bed reactor with two catalytic zones
}

\author{
Margarida M.J. Quina, Rosa M. Quinta Ferreira* \\ Department of Chemical Engineering, University of Coimbra, 3000 Coimbra, Portugal
}

Received 12 November 1998; received in revised form 12 April 1999; accepted 30 April 1999

\begin{abstract}
In this work, comparisons between the behaviour predicted by different types of mathematical models are presented. The system studied was the partial oxidation of methanol to formaldehyde, which occurs in a fixed bed reactor with two distinct zones: at the entrance the catalyst is diluted with inert, followed by a region with pure catalyst. This type of distribution of the catalyst activity leads to different temperature and concentration profiles, when compared with those obtained by a uniform activity bed. Parametric sensitivity is examined for all the dimensionless parameters associated to the different mathematical models of the reactor. The parametric sensitivity analysis shows that the system is particularly sensitive to the wall temperature and almost insensitive to the side reaction and mass transfer parameters. (C) 1999 Elsevier Science S.A. All rights reserved.
\end{abstract}

\section{Introduction}

In the literature, several levels of sophistication of mathematical models have been proposed to study the behaviour of fixed bed reactors, being grouped in two categories: the pseudo-homogeneous (PH) models and heterogeneous (HT) models. The PH models consider the catalyst at the same conditions as the fluid and the HT models account for the differences between temperature and concentration in the bulk phase and temperature and concentration inside the catalyst and at its surface. Each group of mathematical models includes one- or two-dimensional models, in order to take into account the gradients at the reactor scale in less or more detail. Feyo de Azevedo et al. [1] reviewed concepts concerning the modelling and operation of tubular fixed-bed catalytic reactors and discussed alternative approaches to classical models. Pereira Duarte et al. [2,3] studied the performance of different models of fixed-bed catalytic reactors. Rosendall and Finlayson [4] refer criteria to estimate the importance of various phenomena, including heterogeneous effects, density variations, radial dispersion and axial dispersion, pointing out that they can be either significant or negligible depending on the particular cases under analysis. Also Martinez et al. [5] established general criteria, in order to allow a better choice of a reactor model to fulfill the

${ }^{*}$ Corresponding author. Tel.: +351-39-798723; fax: +351-39-798703 E-mail address: eqlrqf@eq.uc.pt (R.M. Quinta Ferreira) objectives of simulation studies. They pointed out that the difference between complex and simple models is, in many cases, of the same order of magnitude as the difference generated by the uncertainty of the parameters. Papageorgiou and Froment [6] showed the importance of the packing structure of the reactor due to significant variation of the void fraction in the radial direction.

In this work steady state models are considered with catalyst dilution of the packing as used in industrial practice. As shown by Froment [7], Pirkle and Wachs [8] and Taniewski et al. [9] the effect of diluting the catalyst, in the first region of the reactor bed with inert packing, makes the heat removal easier and the catalyst bed more effectively used. As a consequence the hot spots are lower and the region of high temperatures are more spread along the catalytic bed. Also, Sofekun et al. [10] studied the effect of the catalyst dilution and presented mathematical equations in order to compute the influence of the dilution on the reactor behaviour. Melis et al. [11] investigated the distribution of the catalyst in order to obtain an optimum behaviour of the reactor, when heterogeneous and homogeneous reactions take place simultaneously.

Since Nir and Pismen [12] studied the influence of the additional mass transport by intraparticle convection, many other studies have been carried out in this area. Rodrigues et al. [13] revisited the intraparticle convection and Quinta Ferreira et al. [14] studied the dynamic behaviour of the fixed bed reactors taking into account that mechanism. In 
this work, the intraparticle convection is also analysed, mainly in what concerns the sensitivity analysis.

Sensitivity analysis provides a systematic framework to study the accuracy and robustness of mathematical models. Ungureanu et al. [15] refer that the aim of sensitivity analysis is to study the influence of small variations of an independent variable (parameter) of the system on a dependent variable (state variable). Parametric sensitivity analysis was first introduced by Tomovic and Vukobratovic in the early 1970's, and since then, it has been applied to numerous fields of engineering as a tool for model building and validation. As pointed out by Caracotsios [16] and Leis et al. [17], potential areas of application in chemical engineering are: model discrimination, optimisation, control system design, parameter estimation, model simplification, process sensitivity and multiplicity and experimental design. In fact, a valuable information can be obtained when parametric variations are calculated, such as the significance of the various parameters, allowing then an easier choice between different mathematical models. Several studies have been carried out in this area. Atherton et al. [18] performed a statistical sensitivity analysis of models for chemical reactors, which allowed to determine the effect of errors in the parameters on the solution of the kinetic equations for a reactor model. Demiralp and Rabitz [19] and Yetter et al. [20] showed that a family of derived sensitivities can be obtained from the elementary ones, and a considerable increase of the usefulness of the sensitivity approach can be reached by this way. Yetter et al. [20] showed how a model originally consisting of 52 elementary reactions and 12 chemical species can be reduced in size to 10 reactions and eight chemical species and still predict the rate and the concentration of $\mathrm{CO}$ oxidation correctly. Kiparissides and Mavridis [21] studied the high-pressure polymerisation of ethylene in tubular reactors. They analysed the effects of design, and the operating and kinetic parameters on the reactor performance. It was shown that the sensitivity analysis can lead to a systematic search for selecting the optimal operating conditions that maximise the reactor productivity. Seferlis and Hrymak [22] developed a methodology for sensitivity analysis in on-line process optimisation. They pointed out that the main interest concerns the study of the changes induced in the optimal values of variables and objective functions under multiple simultaneous parameter perturbations over an expected range of uncertainty. Among others, Rabitz et al. [23] presented the state of the art concerning the sensitivity analysis.

The main objectives of the present paper are centered on the analysis of the behaviour of a fixed bed reactor industrially used for the partial oxidation of methanol to formaldehyde, where the catalytic bed includes two zones of activity, being partially diluted with inert particles at the entrance of the reactor. Different types of mathematical models were used, one- and two-dimensional models and HT and PH models. A sensitivity analysis was performed in order to evaluate the effect on the process behaviour of the variation of the dimensionless parameters included on the different reactor models.

\section{Mathematical models}

The system investigated in this work was the partial oxidation of the methanol to formaldehyde over iron/molybdenum oxides catalyst. The main reaction is the partial oxidation of methanol to formaldehyde, which can be followed by a side reaction involving the partial oxidation of the formaldehyde to $\mathrm{CO}$ and $\mathrm{H}_{2} \mathrm{O}$. Industrially, these reactions take place at $1.4 \mathrm{~atm}$ and $257^{\circ} \mathrm{C}$ and the feed methanol mole fraction is $7.5 \%$ and these were the operating conditions used in this work.

The reactor modelling considers a single tube with a length of $0.75 \mathrm{~m}$, which is divided into two zones: a less active bed in the first region $(0.2 \mathrm{~m}$ of diluted catalyst with $50 \%$ inert) and a second zone with pure catalyst $(0.55 \mathrm{~m})$. This type of distribution of the catalyst allows mild heat generation and also a lower parametric sensitivity when compared with uniform activity reactors.

The reaction of partial oxidation of methanol to formaldehyde has been widely studied. In literature several kinetic models for the main reaction following an oxidation-reduction mechanism can be found [24-27]. We have selected the kinetic model proposed by Dente et al. [24] according to our comparative results between simulated and industrial profiles. For the undesirable consecutive reaction, only a few authors have presented a kinetic model $[27,28]$. We chose the kinetic expression proposed by Dente and Collina [28] also based on a comparison between some industrial profiles and our simulation data.

In this work, different reactor models were used: onedimensional PH model (PH1D), one-dimensional HT models with intraparticle diffusion and convection $\left(\mathrm{HT}_{\mathrm{C}} \mathrm{D}_{\mathrm{dc}}\right)$ or with intraparticle diffusion only $\left(\mathrm{HT}_{\mathrm{D}} \mathrm{D}_{\mathrm{d}}\right)$, and also twodimensional HT models with intraparticle diffusion and convection $\left(\mathrm{HT} 2 \mathrm{D}_{\mathrm{dc}}\right)$ or including only intraparticle diffusion $\left(H T 2 D_{d}\right)$. These mathematical models are based on common assumptions: constant pressure in the reactor, constant values for physical and transport properties, constant wall temperature, constant bed porosity, flat radial velocity profiles (plug flow) and constant catalyst activity in each catalytic zone.

In our work we have considered the effect of temperature and chemical expansion on the variation of the gas velocity along the bed.

\subsection{One-dimensional HT models $\left(H T 1 D_{d c}, H T 1 D_{d}\right)$}

For highly exothermic processes with severe operating conditions, not accounting for the heterogeneity of the catalytic bed may lead to inaccurate model predictions. In this model we assumed isothermal particles, and the mechanism of mass transfer inside the solid could have one 
Table 1

Dimensionless equations for the one-dimensional HT model, with diffusion and convection inside the catalyst, HT1D $\mathrm{D}_{\mathrm{dc}}$

Fluid phase

Mass balance

$$
\frac{\mathrm{d}\left(u^{*} f_{i, \mathrm{~b}}\right)}{\mathrm{d} z^{*}}=D a \sum_{j=1}^{2} \alpha_{i, j} \operatorname{Re}_{j}^{\mathrm{s}} \eta_{j}
$$

Energy balance

$$
\frac{\mathrm{d} \theta_{b}}{\mathrm{~d} z^{*}}=D a \sum_{j=1}^{2} B_{j} \operatorname{Re}_{j}^{\mathrm{s}} \eta_{j}+N_{\mathrm{w}}\left(\theta_{\mathrm{w}}-\theta_{\mathrm{b}}\right)
$$

Initial conditions:

$z^{*}=0, \quad f_{i, \mathrm{~b}}=C_{i, \mathrm{bo}} / C_{\mathrm{M}, \mathrm{o}}, \quad \theta_{\mathrm{b}}=T_{\mathrm{bo}} / T_{\mathrm{o}}$

Fluid/particle interface

Mass balance

$$
-N f_{i}\left(f_{i, \mathrm{~b}}-f_{i, \mathrm{~s}}\right)=D a \sum_{j=1}^{2} \alpha_{i, j} \operatorname{Re}_{j}^{\mathrm{s}} \eta_{j}
$$

Energy balance

$N f_{\mathrm{h}}\left(\theta_{\mathrm{s}}-\theta_{\mathrm{b}}\right)=D a \sum_{j=1}^{2} B_{j} \operatorname{Re}_{j}^{\mathrm{s}} \eta_{j}$

Catalyst particle

Mass balance

$\frac{\mathrm{d}^{2} f_{i, \mathrm{p}}}{\mathrm{d} r_{\mathrm{p}}^{* 2}}-2 \lambda_{\mathrm{m}, i} \frac{\mathrm{d} f_{i, \mathrm{p}}}{\mathrm{d} r_{\mathrm{p}}^{*}}+4 \phi_{i, \mathrm{o}}^{2} \sum_{j=1}^{2} \alpha_{i, j} \operatorname{Re}_{j}^{\mathrm{p}}=0$

Boundary conditions

$\mid \begin{array}{ll}r_{\mathrm{p}}^{*}=0 ; & f_{i, \mathrm{p}}=f_{i, \mathrm{~s}} \\ r_{\mathrm{p}}^{*}=1 ; & f_{i, \mathrm{p}}=f_{i, \mathrm{~s}}\end{array}$

$j=$ number of the reaction

$i=$ methanol; formaldehyde

Model parameters

$N f_{\mathrm{M}}=95.5 ; N f_{\mathrm{F}}=100.4 ; N f_{\mathrm{h}}=118.7 ; N_{\mathrm{w}}=11.49 ; D a=1.04(2.08)^{\mathrm{a}} ; B_{1}=0.729 ; B_{2}=1.071 ; \theta_{\mathrm{w}}=1.0 ; \lambda_{\mathrm{m}, \mathrm{M}}=\lambda_{\mathrm{m}, \mathrm{F}}=10\left(\right.$ for $\mathrm{HT} 1 \mathrm{D}_{\mathrm{dc}}$ model $) ; \lambda_{\mathrm{m}, \mathrm{M}}=$ $\lambda_{\mathrm{m}, \mathrm{F}}=0\left(\right.$ for HT1D $\mathrm{d}$ model); $\phi_{\mathrm{M}, \mathrm{o}}=0.57 ; \phi_{\mathrm{F}, \mathrm{o}}=0.55$

\footnotetext{
${ }^{\mathrm{a}}$ Damkohler number is 1.04 on the first zone of the reactor and 2.08 on the second zone.
}

or two contributions: only diffusion $\left(\mathrm{HT}_{\mathrm{d}} \mathrm{D}_{\mathrm{d}}\right.$ model), or diffusion and convection $\left(\mathrm{HT}_{1} \mathrm{D}_{\mathrm{dc}}\right.$ model). In the external particle film we considered both thermal and mass resistances. The mathematical model HT1D $\mathrm{dc}_{\mathrm{dc}}$ equations and the dimensionless parameters are written in Table 1 and the data of the system are referred in Table 2. To obtain the HT1D model, mass intraparticle Peclet numbers $\lambda_{\mathrm{m}, i}$ in Eq. (6) will be zero $\left(\lambda_{\mathrm{m}, i}=0, i=\mathrm{CH}_{3} \mathrm{OH}, \mathrm{CHOH}\right)$.

\subsection{One-dimensional PH model (PHID)}

This model neglects inter and intraparticle resistances, which leads to the same temperatures values for the bulk and solid phases and, therefore, has been widely used, due to its mathematical simplicity. The corresponding dimensionless

Table 2

Data of the system studied

\begin{tabular}{ll}
\hline Reactor (a single tube) & \\
\hline Length & $\begin{array}{l}L=0.75 \mathrm{~m} \\
\text { Diameter of the tube }\end{array}$ \\
$\begin{array}{l}d_{\mathrm{t}}=0.021 \mathrm{~m} \\
\text { Porosity }\end{array}$ & $\varepsilon_{\mathrm{b}}=0.5$ \\
Specific particle area & $a_{\mathrm{v}}=1285 \mathrm{~m}^{-1}$ \\
Bulk density (pure catalyst) & $\rho_{\mathrm{b}}=1100 \mathrm{~kg} / \mathrm{m}^{3}$ \\
Bulk density (diluted catalyst) & $\rho_{\mathrm{b}}=550 \mathrm{~kg} / \mathrm{m}^{3}$ \\
\hline Catalyst & \\
\hline Equivalent diameter (volume $/$ area) & \\
Density & $d_{\mathrm{pe}}=2.33 \times 10^{-3} \mathrm{~m}$ \\
Porosity & $\rho_{\mathrm{p}}=2200 \mathrm{~kg} / \mathrm{m}^{3}$ \\
Slab half thickness & $\varepsilon_{\mathrm{p}}=0.5$ \\
\hline
\end{tabular}

equations can be obtained from the equations of the fluid phase presented in Table 1 for the HT1D ${ }_{\mathrm{dc}}$ model (Eqs. (1)(3)) by assuming the effectiveness factors of the catalyst particles equal to one (Eqs. (1)-(2) $\left.\eta_{j}=1(j=1,2)\right)$. The dimensionless parameters in this case are only $D a, B_{1}, B_{2}$, $N_{\mathrm{w}}$ and $\theta_{\mathrm{w}}$, which have the same values as those indicated in Table 1.

\subsection{Two-dimensional HT models $\left(H T 2 D_{d c}, H T 2 D_{d}\right)$}

Since the process is exothermic, significant radial temperature profiles can be observed, and therefore, bidimensional models must be used. The contribution of the solid phase to the thermal transport which can be important [29] was taken into account by using an effective thermal radial dispersion parameter, $\lambda_{\mathrm{er}}$, calculated through the correlation proposed by Dixon and Cresswell [30]. The equations of the HT2 $D_{\mathrm{dc}}$ model are those indicated in Table 1, for the onedimensional model, replacing now Eqs. (1)-(3) for the following Eqs. (8)-(10c):

$$
\begin{aligned}
& \text { Mass balance } \frac{\partial\left(u^{*} f_{i, \mathrm{~b}}\right)}{\partial z^{*}}=\frac{L^{2}}{R_{\mathrm{t}}^{2}} \frac{1}{P e_{\mathrm{mr}}} \frac{1}{r^{*}} \frac{\partial}{\partial r^{*}}\left(r^{*} \frac{\partial f_{i, \mathrm{~b}}}{\partial r^{*}}\right) \\
& +D a \sum_{j=1}^{2} \alpha_{i, j} \operatorname{Re}_{j}^{\mathrm{s}} \eta_{j} \\
& \text { Energy balance } \quad \frac{\partial \theta_{\mathrm{b}}}{\partial z^{*}}=\frac{L^{2}}{R_{\mathrm{t}}^{2}} \frac{1}{P e_{\mathrm{hr}}} \frac{1}{r^{*}} \frac{\partial}{\partial r^{*}}\left(r^{*} \frac{\partial \theta_{\mathrm{b}}}{\partial r^{*}}\right) \\
& +D a \sum_{j=1}^{2} B_{j} \operatorname{Re}_{j}^{\mathrm{s}} \eta_{j}
\end{aligned}
$$


Initial conditions $\quad z^{*}=0, \quad f_{i, \mathrm{~b}}=\frac{C_{i, \mathrm{bo}}}{C_{\mathrm{M}, \mathrm{o}}}, \quad \theta_{\mathrm{b}}=\frac{T_{\mathrm{bo}}}{T_{\mathrm{o}}}$

Boundary conditions $\quad r^{*}=0, \quad \frac{\partial f_{i, \mathrm{~b}}}{\partial r^{*}}=\frac{\partial \theta_{\mathrm{b}}}{\partial r^{*}}=0$

$r^{*}=1 \mid \begin{aligned} & \partial f_{i, \mathrm{~b}} / \partial r=0 \\ & -\partial \theta_{\mathrm{b}} / \partial r=B i_{\mathrm{w}}\left(\theta_{\mathrm{b}}-\theta_{\mathrm{w}}\right)\end{aligned}$.

The dimensionless model parameters in this case are $P e_{\mathrm{mr}}=2791.3 ; \quad N f_{\mathrm{M}}=95.5 ; \quad N f_{\mathrm{F}}=100.4 ; \quad P e_{\mathrm{hr}}=852.4$; $N f_{\mathrm{h}}=118.7 ; \quad D a=1.04 \quad(2.08) ; \quad B_{1}=0.729 ; \quad B_{2}=1.071 ;$ $B i_{\mathrm{w}}=1.263 ; \theta_{\mathrm{w}}=1.0 ; \alpha^{\prime}=5102$. When the radial Peclet numbers are defined as function of the particle diameter, their values are $P e_{\mathrm{mr}}\left(d_{\mathrm{pe}}\right)=8.7$ and $P e_{\mathrm{hr}}\left(d_{\mathrm{pe}}\right)=2.6$.

\section{Numerical methods}

The model equations for the PH1D are ordinary differential equations, ODE's, and for the HT1D $\mathrm{dc}_{\mathrm{c}}$ and $\mathrm{HT}_{\mathrm{d}}$ models a system of differential and algebraic equations is obtained, DAE's, since the fluid/intraparticle resistances are represented by algebraic equations. Being one of the objectives of the present work focused on the calculation of the sensitivity coefficients, the DDASAC package was used [31], which is an extension of DASSL code, developed by Petzold [32].

Leis and Kramer [33] referred that the simplest approach to determine the sensitivity of a mathematical model involves one-at-a-time parameter perturbation and repeated resolution of the model. However, nowadays, there are some sophisticated algorithms to solve the sensitivity equations. Those authors classified the different algorithms into two general categories: sequential methods and simultaneous methods. Caracotsios and Stewart [31] tried to exploit the advanced status of implicit integrators to develop a robust software to perform the computation of sensitivity functions for general systems of mixed algebraic and differential equations, namely DDASAC, taking advantage of the similarity between the sensitivity and state equations.

To solve the model equations, PDE's, and calculate the sensitivities functions for the bidimensional models $\left(H T 2 \mathrm{D}_{\mathrm{d}}\right.$ and $\mathrm{HT} 2 \mathrm{D}_{\mathrm{dc}}$ ), orthogonal collocation on finite elements was used to discretize by hand the radial coordinate of the reactor, being the methodology of this discretization detailed elsewhere [34]. The resulting system of DAEs was also solved by the package DDASAC. The number of collocation points is critical in adjusting the velocity of the calculations. As pointed out by Windes et al. [27], and also confirmed in the present work, two radial finite elements (each one with two points of collocation) is a good compromise between the quality of the solution and the computing time. To solve Eq. (6), in order to obtain intraparticle concentration profiles to be used in the calculation of the effectiveness factors of the catalysts for the HT models, we also used the method of orthogonal collocation on finite elements.

The mathematical models previously mentioned could be written in the general following way:

$$
\begin{aligned}
& \boldsymbol{E} \boldsymbol{u}^{\prime}(t)=f(t, u(t) ; \phi) \\
& \text { Initial condition } \quad \boldsymbol{u}\left(t=t_{\mathrm{o}}\right)=t_{\mathrm{o}}(\phi)
\end{aligned}
$$

where $\boldsymbol{u}$ is an $n$-dimensional vector of state variables, $\phi$ is an $m$-dimensional vector of time-independent parameters and $\boldsymbol{E}$ is a $n \times n$ matrix of constant coefficients. Caracotsios and Stewart [31] defined the $n \times m$ matrix $\boldsymbol{W}(t)$ of the sensitivity functions as

$\boldsymbol{W}(t)=\frac{\partial \boldsymbol{u}(t)}{\partial \phi}$

This matrix can be derived by partial differentiation of the state equations with respect to the parameter vector $\phi$. Since the reactor equations are integrated in the axial direction, a sensitivity matrix for each axial point $z$ is determined and so, sensitivity axial profiles were obtained. In some circumstances, it is also convenient to analyse the normalised sensitivities profiles, which are defined through the Eq. (14).

$\boldsymbol{S}\left(u_{k} ; \phi_{i}\right)=\frac{\phi_{i}}{u_{k, \mathrm{o}}} \frac{\partial u_{k}}{\partial \phi_{i}}$

The advantage of the normalised coefficients rather than the non-normalised ones is related to their relative character, and then they can be directly compared with each other.

As referred by Yetter et al. [20]. Kiparissides and Mavridis [21], Leis et al. [17] and Ungureanu et al. [15] these coefficients represent the percentage variation in $u_{k}$ due to a positive percentage variation in $\phi_{i}$ for a linear approximation. Then, for small perturbations on the parameters, we could approximate the sensitivity coefficients by:

$\frac{\partial u_{k}}{\partial \phi_{i}} \simeq \frac{\Delta u_{k}}{\Delta \phi_{i}}$

and then it can be found that:

$\Delta u_{k}=\frac{u_{k, \mathrm{o}}}{\phi_{i}} \boldsymbol{S}\left(u_{k} ; \phi_{i}\right) \Delta \phi_{i}$

So, once the matrix sensitivities are known, it would be possible to calculate the state variables variation after a known variation on the parameters, $\phi_{i}$, only in the case of small variations. From the above equation, it can be found in those circumstances an analogy between the sensitivity concept and the steady state gain, because both have identical properties: they represent a ratio between two quantities and admit linearity.

\section{Computer results}

The steady state behaviour of a fixed bed reactor, where the methanol oxidation takes place, was studied by solving 


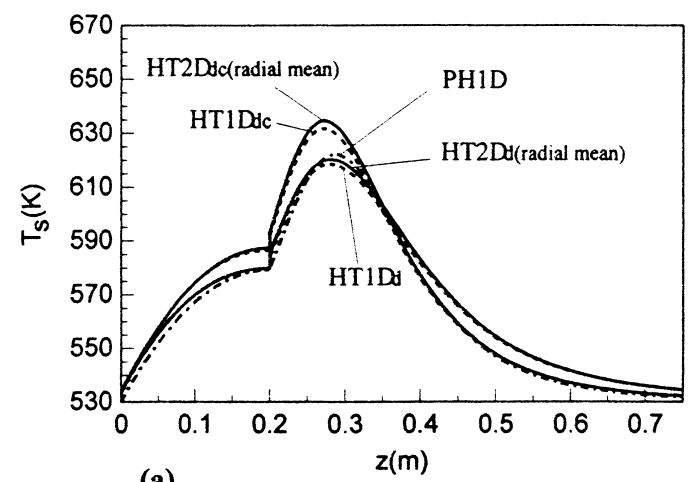

(a)

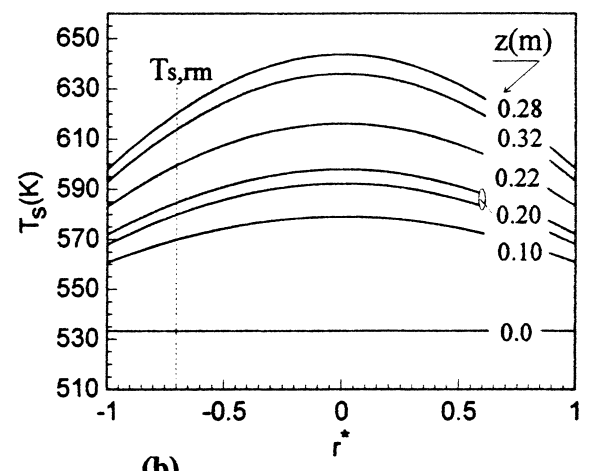

(b)

Fig. 1. (a) Axial solid temperature profiles predicted with different mathematical models: PH1D, HT1D $\mathrm{d}_{\mathrm{d}}, \mathrm{HT}_{\mathrm{dc}}, \mathrm{HT} 2 \mathrm{D}_{\mathrm{d}}$, HT2D $\mathrm{D}_{\mathrm{dc}}$; (b) Radial solid temperature profiles predicted with $\mathrm{HT}_{2} \mathrm{D}_{\mathrm{d}}$ model.

different types of mathematical models: PH1D, HT1D $\mathrm{HT}_{\mathrm{dc}}$, HT2D, $\mathrm{HT} 2 \mathrm{D}_{\mathrm{dc}}$.

Fig. 1(a) shows the steady-state axial profiles for the catalyst temperature, predicted by the different reactor models and as can be seen the results of the HT1D PH1D and HT2D (radial mean) are quite similar, for this moderate steady state conditions (industrial conditions). Although the simulations of the bidimensional model $\mathrm{HT} 2 \mathrm{D}_{\mathrm{d}}$ predicted significant radial temperature profiles $\left(\approx 50^{\circ} \mathrm{C}\right)$, Fig. $1(\mathrm{~b})$, the radial mean values are close to those obtained by the HT1D $\mathrm{d}_{\mathrm{d}}$ model. Therefore, the more complex model (HT2D model) has to be used when the knowledge of the local parameters of the system is required, which can be important for the detection of the higher temperatures of the bulk leading to a local deactivation of the catalyst. The times required to compute those results are very different depending on the type of the model used for the simulations. Using a SUN SPARC 10/52 computer, the time needed to solve the PH1D model is only a few seconds (3-4 s) and for the $\mathrm{HT}_{1} \mathrm{D}_{\mathrm{d}}$ model a few minutes (4$5 \mathrm{~min}$ ). However, to simulate the $\mathrm{HT}_{2} \mathrm{D}_{\mathrm{d}}$ model the time spent is $30-35 \mathrm{~min}$.

As can be seen from Fig. 1(a), and for the operating conditions considered in this study, all the mathematical models predicted hot spots located in the second zone of the bed (packed with only catalyst particles). However, depending on the operating conditions, it is also possible to obtain thermal profiles with a hot spot located in the first zone of the catalyst bed, or even with two hot spots (one in each zone). It is worth stressing that there is a wider zone of high temperatures along the reactor with a lower hot spot when compared to the case with pure catalyst along the entire bed, since the heat released by chemical reaction in the diluted region is not so intense as in the case where there is no catalyst dilution.

As expected, the additional convective flow inside the catalyst particles leads to an improvement of the catalyst effectiveness factor, and consequently, the hot spots are higher than those obtained with the other models considering only intraparticle mass flux by diffusion. Once again, the predictions obtained for the mean radial values of the $2 \mathrm{D}$ model, HT2 $\mathrm{D}_{\mathrm{dc}}$, and those obtained with the 1D model, $\mathrm{HT}_{1 \mathrm{D}}$, are in good agreement.

Fig. 2(a) represents the velocity profile for the PH model, which shows an increase of $21 \%$ in the hot spot region. In order to evaluate the effect of the film resistances, we compared, in Fig. 2(b), the results obtained with the onedimensional HT model neglecting the resistances in the film surrounding the catalyst particles and those obtained with the complete HT model considering the external and internal resistances. For the hot spot region, the predictions point out a thermal gradient in the film (difference between the fluid temperature, $T_{\mathrm{b}}$, and the solid temperature, $T_{\mathrm{s}}$ Fig. 2(b), dashed lines) of $8 \mathrm{~K}$. If this temperature gradient is
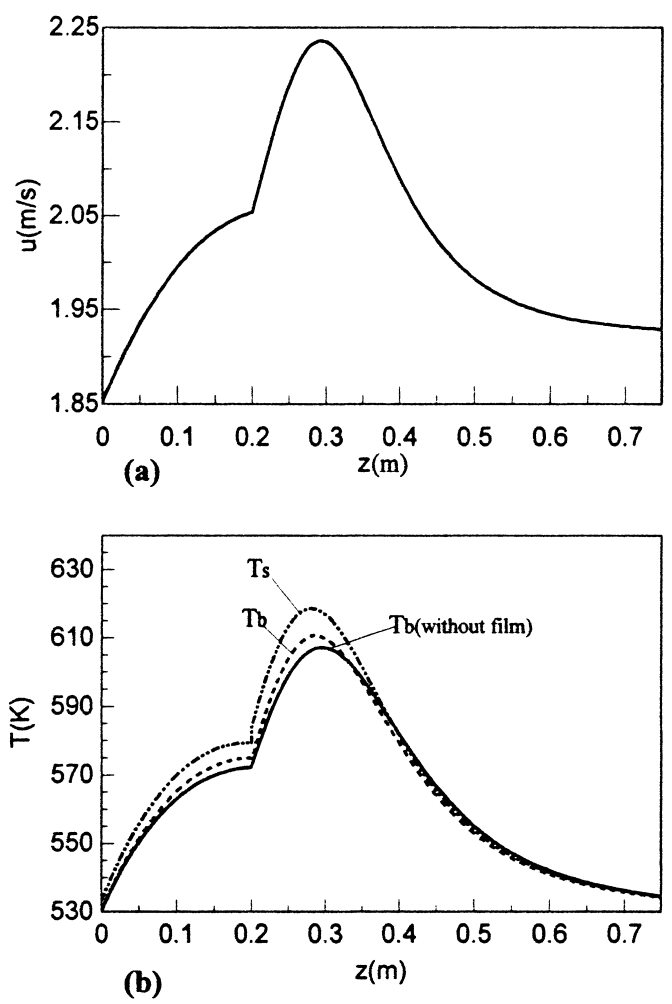

Fig. 2. (a) Axial profile of the gas velocity for the PH1D model; (b) Axial temperature profiles predicted by the HT1D $\mathrm{D}_{\mathrm{d}}$ model with and without film resistances. 
neglected, by neglecting the film resistances, the maximum temperature of the catalytic bed, $T_{\mathrm{b}}$, (which is now equal to $T_{\mathrm{s}}$, Fig. 2(b), full line) will be lowered by $11 \mathrm{~K}$. In spite of being possible the use of a simple HT model considering only resistances inside the particles, which is also pointed out by the high values of the film transfer parameters, we included on the mathematical models the film resistances along the bed, since they represent a more realistic approach to the system. The simplification of the model if the external resistances were not considered could lead to a decrease of $1.1 \mathrm{~min}$ on the computational time. We would have then a CPU time of 3.4 min (using a SUN SPARC 10/52 computer) if external resistances were neglected instead of $4.5 \mathrm{~min}$ when they are taken into account, which are quite reasonable CPU times. For the two-dimensional models, if the external resistances were neglected a higher decrease in the CPU time would be obtained $(53 \%, 14 \mathrm{~min}$ instead of $30 \mathrm{~min}$ ) but the temperature differences predicted with and without film resistances would also be higher (14 K for the hot spot in the center of the reactor). Therefore, in spite of being possible to use heterogenous models without external resistances, these resistances were included in the mathematical models used in the present work. However, if the reactor models were included in a control analysis of the system those gains in CPU times would be advantageous and a strategy of neglecting external gradients would be convenient.

From the model equations of Table 1, it can be observed that the one-dimensional HT models $\left(\mathrm{HT}_{1} \mathrm{D}_{\mathrm{d}}\right.$ and HT1D $\left.\mathrm{Dc}_{\mathrm{dc}}\right)$ are defined through several dimensionless parameters $\left(N f_{\mathrm{M}}\right.$, $\left.N f_{\mathrm{F}}, N f_{\mathrm{h}}, N_{\mathrm{w}}, D a, B_{1}, B_{2}, \theta_{\mathrm{w}}\right)$ and state variables $\left(f_{\mathrm{M}, \mathrm{b}}, f_{\mathrm{F}, \mathrm{b}}, \theta_{\mathrm{b}}\right.$, $\left.\theta_{\mathrm{s}}, f_{\mathrm{M}, \mathrm{s}}, f_{\mathrm{F}, \mathrm{s}}\right)$. Among the state variables of the system, we are going to analyse here only two of them $\left(f_{\mathrm{M}, \mathrm{b}}, \theta_{\mathrm{s}}\right)$, since the general conclusions obtained with the other variables are the same.

For the feed temperature of $530 \mathrm{~K}$, Fig. 3 shows the normalised sensitivity profiles of the methanol concentration, $f_{\mathrm{M}, \mathrm{b}}$, related to all the model parameters, $\boldsymbol{S}\left(f_{\mathrm{M}, \mathrm{b}} ; \phi_{i}\right)$. From these results it can be concluded that for the operating conditions studied, the most influent dimensionless parameters, on the methanol concentration profile, are $\theta_{\mathrm{w}}, D a$,

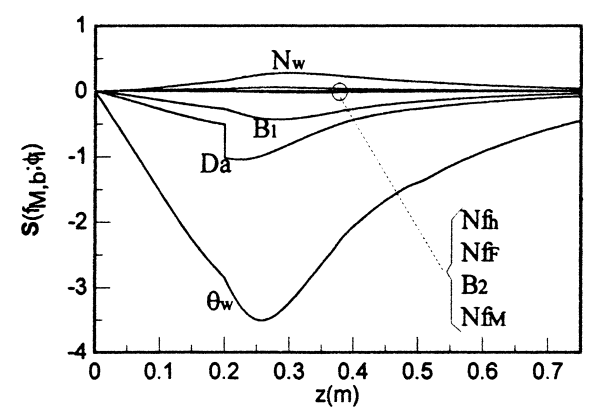

Fig. 3. Normalised sensitivity profiles of the reactant concentration, $f_{\mathrm{M}, \mathrm{b}}$ for various input parameters, $\phi_{i}=\theta_{\mathrm{w}} ; D a ; B_{1} ; N N_{\mathrm{w}} ; N f_{\mathrm{h}} ; N f_{\mathrm{F}} ; N f_{\mathrm{M}} ; B_{2}$. Model HT1D $; T_{\mathrm{o}}=530 \mathrm{~K}$.
$B_{1}$, and $N_{\mathrm{w}}$, and those which are less influent are $N f_{\mathrm{h}}, N f_{\mathrm{M}}$, $B_{2}, N f_{\mathrm{F}}$. The wall temperature, $\theta_{\mathrm{w}}$, is the parameter with a higher effect on the behaviour of the process, since it shows more pronounced sensitivities. The jump observed on the sensitivity profile related with $D a$ on the transition between the two zones of the reactor with different catalytic activity, is due to its different values (in the second zone $D a$ is twice its value on the first part of the reactor). Since the numbers of film transfer units are high, the predictions obtained with the HT and PH models must be close, and a low influence of these numbers is expected, not only on the methanol concentration but also on any other state variable.

One can also observe that some parameters lead to positive sensitivity coefficients $\left(N f_{\mathrm{F}}, N f_{\mathrm{h}}\right.$ and $\left.N_{\mathrm{w}}\right)$ while others originate negative sensitivity profiles $\left(N f_{\mathrm{M}}, D a, B_{1}\right.$, $B_{2}$ and $\theta_{\mathrm{w}}$ ). When a sensitivity coefficient is positive an increase in the model parameter leads to an increase in the corresponding state variable, and when it is negative an increase in the parameter leads to a decrease of the state variable. For instance, if the wall temperature, $\theta_{\mathrm{w}}$, increases there is a higher consumption of methanol which makes its concentration to be lowered and, contrarily, if $N_{\mathrm{w}}$, increases, the heat transfer at the reactor wall increases being then the catalytic bed at a lower temperature with a higher methanol concentration.

Fig. 4 shows the normalised sensitivity profiles of the solid temperature, $\theta_{\mathrm{s}}$, related to all the model parameters, $\boldsymbol{S}\left(\theta_{\mathrm{s}} ; \phi_{i}\right)$. We also included the normalised temperature profile, $\theta_{\mathrm{s}}(z)$ in order to show that the maximum of the sensitivity coefficients and the maximum temperature can occur in different locations of the bed. However, the axial sensitivity functions are strongly influenced by the temperature evolution along the reactor, the system being more sensitive near the hot spot zone. At the inlet and outlet of the reactor all the sensitivity functions are very small (approaching zero), except the sensitivity of the solid temperature related to wall temperature, $\boldsymbol{S}\left(\theta_{\mathrm{s}} ; \theta_{\mathrm{w}}\right)$. In fact, the dimensionless parameter $\theta_{\mathrm{w}}$ has a strong effect over all the reactor length as seen before.

In this case, the hierarchy of the effect of the parameters on the solid temperature profile is quite similar to their effect

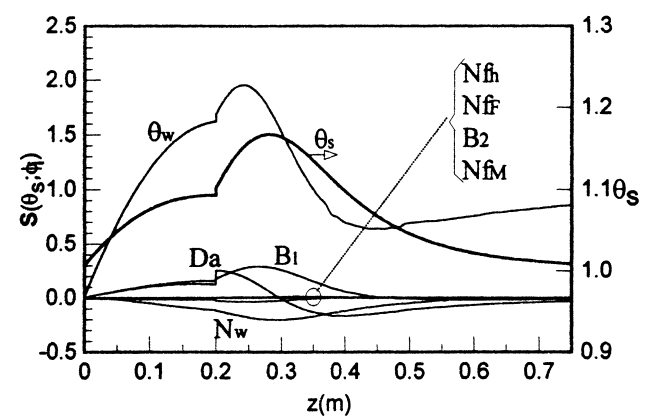

Fig. 4. Normalised sensitivity profiles of the solid temperature, $\theta_{\mathrm{s}}$, for various input parameters, $\phi_{i}=\theta_{\mathrm{w}} ; D a ; B_{1} ; N_{\mathrm{w}} ; N f_{\mathrm{h}} ; N f_{\mathrm{F}} ; N f_{\mathrm{M}} ; B_{2}$. Model $\mathrm{HT} 1 \mathrm{D}_{\mathrm{d}} ; T_{\mathrm{o}}=530 \mathrm{~K}$ 


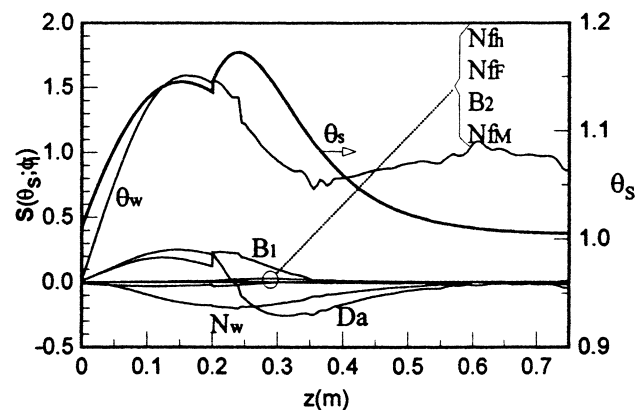

Fig. 5. Normalised sensitivity profiles of the solid temperature, $\theta_{\mathrm{s}}$, for various input parameters, $\phi_{i}=\theta_{\mathrm{w}} ; D a ; B_{1} ; N_{\mathrm{w}} ; N f_{\mathrm{h}} ; N f_{\mathrm{F}} ; N f_{\mathrm{M}} ; B_{2}$. Model $\mathrm{HT} 1 \mathrm{D}_{\mathrm{d}} ; T_{\mathrm{o}}=570 \mathrm{~K}$.

on the methanol concentration; $\theta_{\mathrm{w}}>B_{1}, D a, N_{\mathrm{w}}>N f_{\mathrm{h}}>B_{2}$ $>N f_{\mathrm{M}}>N f_{\mathrm{F}}$. As it is possible to observe, the parameter related with the secondary reaction, $B_{2}$ has a small effect on the reactor behaviour, which allows us to conclude that for the range of operating conditions studied, the effect of the side reaction could be neglected. It is interesting to note that the sensitivity functions change from positive to negative and from negative to positive when they are calculated for the methanol concentration (Fig. 3) and for the solid temperature (Fig. 4). In fact, the evolution of these variables goes in different directions, i.e., an increase in the catalyst temperature leads to a higher consumption of the methanol with the corresponding decrease of its concentration.

For a higher feed temperature, $T_{\mathrm{o}}=570 \mathrm{~K}$, Fig. 5 shows the sensitivity profiles of the solid temperature for all the dimensionless parameters. We also included the solid temperature profile, and as can be observed, for these operating conditions two hot spots can be found (one in each zone of the reactor). The hierarchy of the effect of all parameters is the same as mentioned above, being once more the wall temperature the most important parameter for the reactor behaviour. The sensitivity functions exhibit in this case some numerical 'noise', which is due to the more strong operating conditions. The influence of the side reaction, $B_{2}$, in spite of being somehow higher, is still not very significant.

We have also considered the initial conditions as parameters in order to study their sensitivity functions, since they can give important information regarding the behaviour of the reactor. Fig. 6 represents sensitivity profiles for the methanol concentration (in Fig. 6(a)), formaldehyde concentration (in Fig. 6(b)) and solid temperature (in Fig. 6(c)), with respect to the inlet temperature. $T_{\mathrm{o}}$. and to the inlet methanol concentration, $C_{\mathrm{M}, \mathrm{o}}$. We also included in each case the profiles of the state variable related with the corresponding sensitivity profile, $S\left(u_{k} ; \phi_{i}\right),\left(C_{\mathrm{M}, \mathrm{b}}(z)\right.$ in Fig. $6(\mathrm{a}), C_{\mathrm{F}, \mathrm{b}}(z)$ in Fig. 6(b), and $T_{\mathrm{s}}(z)$ in Fig. 6(c)). For the range of operating conditions analysed, it can be concluded that the inlet conditions have a strong effect in the initial part of the reactor. In the second part, the sensitivity decreases when the distance from the reactor inlet increases, and at the exit the sensitivity coefficients are nearly zero for the methanol concentration and solid temperature but not for the formaldehyde concentration.

Fig. 6(a) shows that when the inlet methanol concentration, $C_{\mathrm{M}, \mathrm{o}}$, increases, the methanol concentration in the first part of the reactor also increases (positive sensitivity coefficients), but nearby the hot spot $C_{\mathrm{M}, \mathrm{b}}$ decreases (negative
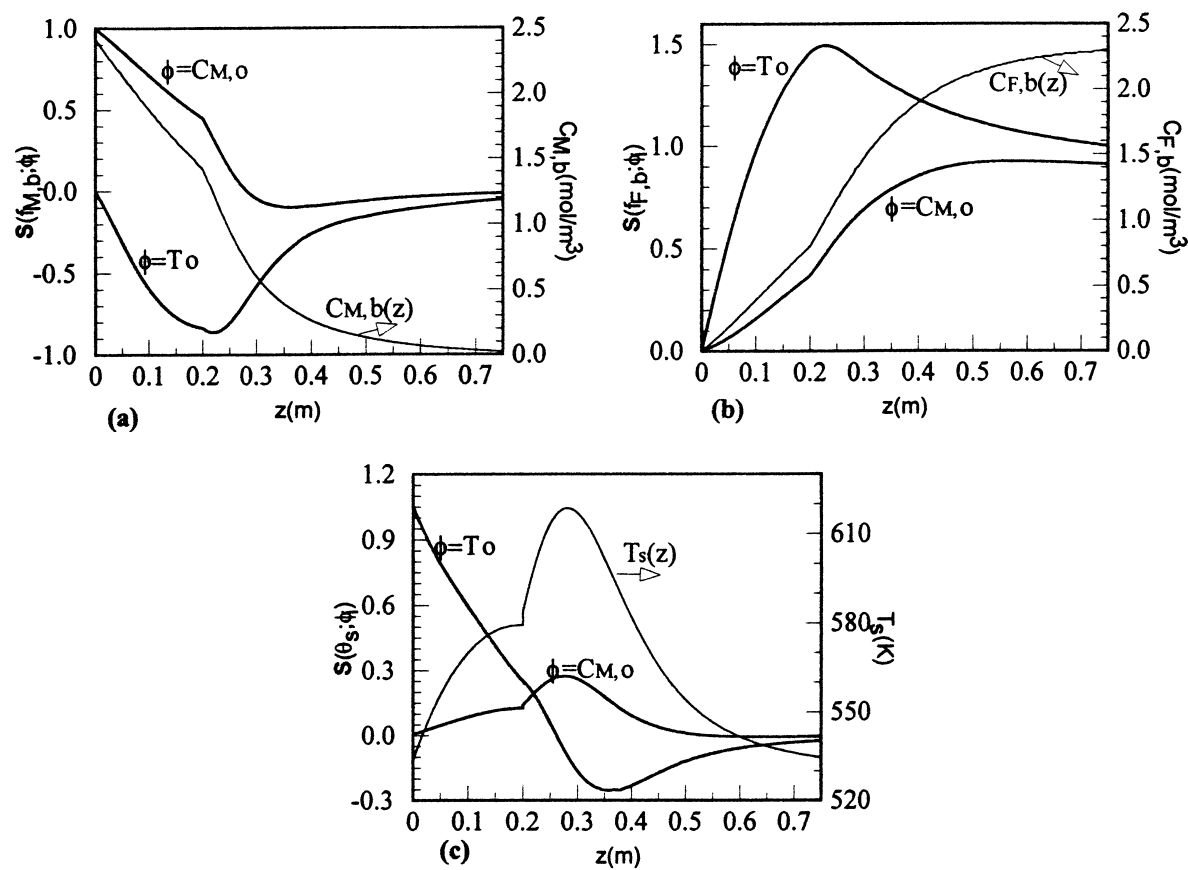

Fig. 6. Normalised sensitivity profiles: (a) methanol concentration in the bulk (b) formaldehyde concentration in the bulk; (c) solid temperature, $\theta_{\mathrm{s}}$; for $\phi_{i}=f_{\mathrm{M}, \mathrm{o}}$ and $\phi_{i}=\theta_{\mathrm{o}}$. Model HT1D . 
sensitivity coefficients). This means that the rate of depletion of methanol is higher when the inlet concentration is also higher. An increase of the feed temperature, $T_{\mathrm{o}}$, leads also to the increase of the velocity of the reaction, and then the methanol concentration decreases in the first part of the reactor.

As can be seen in Fig. 6(b). the effect of an increase on the feed temperature, $T_{\mathrm{o}}$, leads to an increase on the formaldehyde concentration over the entire reactor and the same is observed for the methanol concentration, $C_{\mathrm{M}, \mathrm{o}}$. So, an increase of the formaldehyde concentration at the reactor exit can be obtained by increasing the feed temperature and methanol concentration while methanol is the limiting reactant (however, it will be necessary to take into account the explosion limits of the feed mixture). In fact, due to the presence of the secondary reaction involving the depletion of formaldehyde, it will be necessary to avoid the operating conditions that can favour this reaction with respect to the main reaction. Finally, Fig. 6(c) shows that an increase on the feed methanol concentration, $C_{\mathrm{Mo}}$, leads to the temperature increase in all the extension of the reactor, this effect being more significant in the hot spot zone. The increase of $T_{\mathrm{o}}$ also originates higher temperatures in the first part of the reactor (positive sensitivity coefficients) but lower values on the second part. With higher feed temperatures the reaction rate increases, and so the methanol consumption is faster in the first part of the reactor. Consequently, lower quantities of methanol will be present down in the reactor, which will lead to lower reaction rates and lower bed temperatures.

When an additional flux of mass is introduced inside the catalyst particles by convection $\left(\lambda_{\mathrm{m}, i}=10\right)$, an identical behaviour of the sensitivity profiles is observed (Fig. 7(a)), with higher sensitivity coefficients until the hot spot zone than the ones obtained before by considering only intraparticle diffusion (Fig. 4). So, the system becomes more sensitive, as can be observed in Fig. 7(b), where the sensitivity profiles with respect to $\theta_{\mathrm{w}}$ are compared in both cases: $\lambda_{\mathrm{m}, i}=10$ and 0 . In fact, when intraparticle convection is taken into account more reactant enters the catalyst leading to higher reaction rates with more heat released. However,

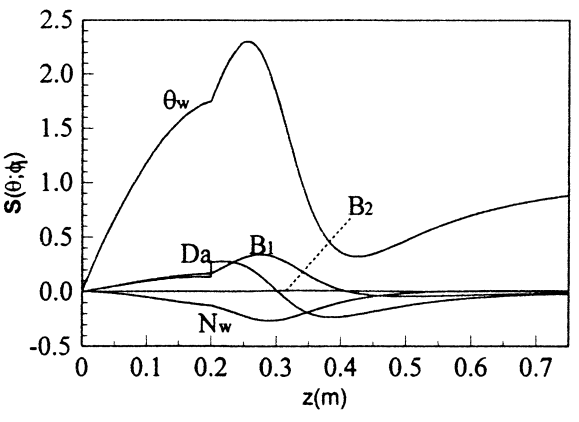

Fig. 8. Normalised sensitivity profiles of the temperature for various input parameters, $\phi_{i}=\theta_{\mathrm{w}} ; D a ; B_{1} ; N_{\mathrm{w}} ; B_{2}$. Model PH1D; $T_{\mathrm{o}}=530 \mathrm{~K}$.

further in the reactor, the reactant quantity will be lower which will reverse the situation in relation to the case where only diffusion is considered, then the system becoming more sensitive for $\lambda_{\mathrm{m}, i}=0$.

The PH model (PH1D) is described by five parameters $\left(N_{\mathrm{w}}, D a, B_{1}, B_{2}, \theta_{\mathrm{w}}\right)$ which are also common to the HT models $\left(H T 1 D_{d}, H T 1 D_{d c}\right)$. So, we can compare Figs. 4 and 8 , and as can be seen, the sensitivity coefficients predicted by the PH1D model (Fig. 8) are similar to those obtained with the HT models

In the two-dimensional model equations (HT2D, Eqs. (4)-(10c)) one can identify several dimensionless parameters $\left.P e_{\mathrm{mr}}, P e_{\mathrm{hr}}, N f_{\mathrm{M}}, N f_{\mathrm{F}}, N f_{\mathrm{h}}, B i_{\mathrm{w}}, D a, B_{1} B_{2}, \theta_{\mathrm{w}}, \alpha^{\prime}\right)$. Some of them are difficult to estimate, and so it will be important to find out the effect of each one of these parameters in the state variables solution. The calculation of the sensitivity functions for this model requires a considerable amount of time, because the dimension of the problem is much higher than for one-dimensional models. It is worth noting that the six PDA's, which describe the HT2D model, lead to 30 DAE's after discretization of the radial coordinate by orthogonal collocation in two finite elements which were solved by the DDASAC code. Since there are 11 dimensionless parameters, the number of sensitivity equations that have to be solved are $11 \times 30$, being the time required to solve this problem $\approx 30-35 \mathrm{~min}$ in a SUN SPARC $10 / 52$ computer. Due to the bidimensional nature of the system
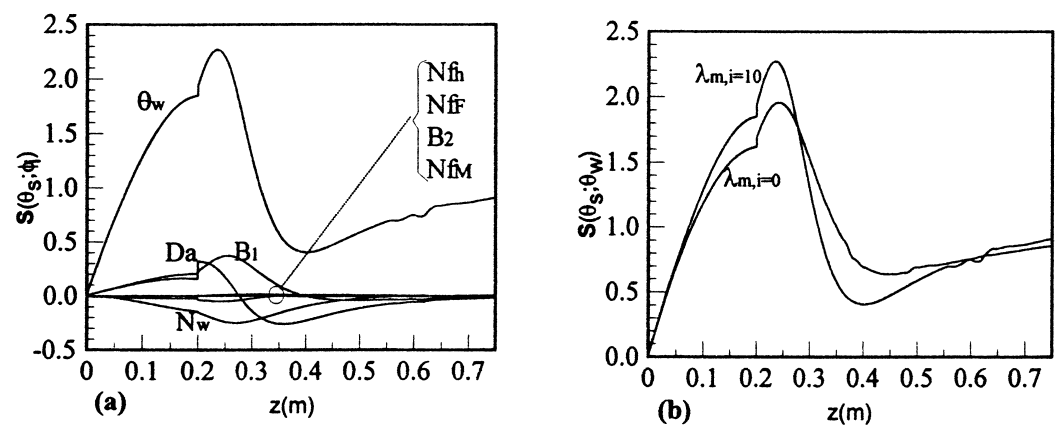

Fig. 7. Normalised sensitivity profiles of the solid temperature, $\theta_{\mathrm{s}}$ and $T_{\mathrm{o}}=530 \mathrm{~K}$ : (a) for various input parameters, $\phi_{i}=\theta_{\mathrm{w}} ; D a ; B_{1} ; N_{\mathrm{w}} ; N f_{\mathrm{h}} ; N f_{\mathrm{F}} ; N f_{\mathrm{M}} ; B_{2}$; and $\lambda_{\mathrm{m}, i}=10$; Model HT1D $\mathrm{dc}$; (b) comparison between HT1D $\left.\mathrm{dc}_{\mathrm{m}, i}=10\right)$ and $\mathrm{HT}_{1} \mathrm{D}_{\mathrm{d}}\left(\lambda_{\mathrm{m}, i}=0\right)$ for $\phi_{i}=\theta_{\mathrm{w}}$. 


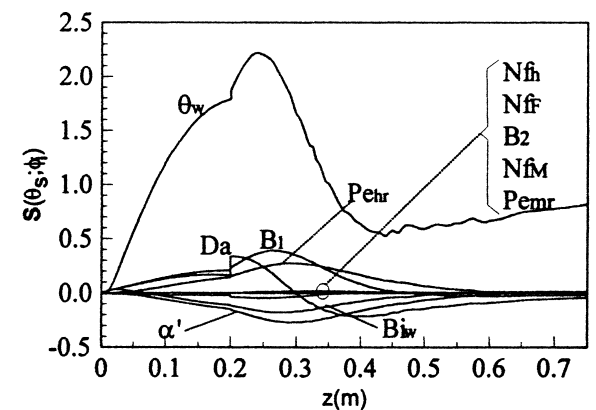

Fig. 9. Normalised sensitivity profiles of the solid temperature, $\theta_{\mathrm{s}}$, on the reactor axis for various input parameters, $\phi_{i}=\theta_{\mathrm{w}} ; D a ; B_{1} ; N f_{\mathrm{h}} ; N f_{\mathrm{F}} ; N f_{\mathrm{M}}$; $B_{2} ; P e_{\mathrm{mr}}, P e_{\mathrm{h},}, B i_{\mathrm{w}}, \alpha^{\prime}$. Model HT2D $; T_{\mathrm{o}}=530 \mathrm{~K}$.

there is now a sensitivity matrix for each axial and radial position. The simulation results showed that in general, at the centre of the reactor, the sensitivity is higher than close to the reactor wall. So, we will refer mainly the behaviour of the sensitivities along the reactor axis.

Fig. 9 shows the sensitivity of the solid temperature with respect to these 11 parameters. Once again, the most important dimensionless parameter is the wall temperature $\left(\theta_{\mathrm{w}}\right)$, which must be chosen carefully. If we look at the hot spot zone, we can establish the following ranking: $\boldsymbol{S}\left(\theta_{\mathrm{s}} ; \theta_{\mathrm{w}}\right)>\boldsymbol{S}\left(\theta_{\mathrm{s}} ; B_{1}\right)>\boldsymbol{S}\left(\theta_{\mathrm{s}} ; D a\right)>\boldsymbol{S}\left(\theta_{\mathrm{s}} ; P e_{\mathrm{hr}}\right)$ and $\boldsymbol{S}\left(\theta_{\mathrm{s}} ; \alpha^{\prime}\right)>$ $\boldsymbol{S}\left(\theta_{\mathrm{s}} ; B i_{\mathrm{w}}\right)>\boldsymbol{S}\left(\theta_{\mathrm{s}} ; N f_{\mathrm{h}}\right)>\boldsymbol{S}\left(\theta_{\mathrm{s}} ; B_{2}\right)>\boldsymbol{S}\left(\theta_{\mathrm{s}} ; N f_{\mathrm{M}}\right)>\boldsymbol{S}\left(\theta_{\mathrm{s}} ; P e_{\mathrm{mr}}\right)>$ $\boldsymbol{S}\left(\theta_{\mathrm{s}} ; N f_{\mathrm{F}}\right)$.

Among the specific dimensionless parameters for the two-dimensional models $\left(P e_{\mathrm{hr}}, \alpha^{\prime} B i_{\mathrm{w}}, P e_{\mathrm{mr}}\right.$ the most influent in the reactor behaviour are $P e_{\mathrm{hr}}$ and $B i_{\mathrm{w}}$, and therefore, they must be calculated more carefully. The geometrical parameter $\alpha^{\prime}$ has also a significant influence on the temperature profile, and so it is important to choose thoughtfully the reactor dimensions ( $L$ and $R_{\mathrm{t}}$ ) in the design of the system. On the other hand, the parameters related with mass transfer $\left(N f_{\mathrm{M}}, P e_{\mathrm{mr}}, N f_{\mathrm{F}}\right)$ do not have a great influence on the reactor behaviour.

\section{Conclusions}

A model comparison and a sensitivity analysis have been carried out by considering several mathematical models: one-dimensional HT model which takes into account intraparticle convection and diffusion $\left(\mathrm{HT}_{1} \mathrm{D}_{\mathrm{dc}}\right)$; one-dimensional HT model which considers only intraparticle diffusion $\left(\mathrm{HT}_{1} \mathrm{D}_{\mathrm{d}}\right)$; two-dimensional HT model with intraparticle convection and diffusion $\left(\mathrm{HT} 2 \mathrm{D}_{\mathrm{dc}}\right)$; two-dimensional HT model where the only transport mechanism inside the catalyst is diffusion $\left(\mathrm{HT}_{2} \mathrm{D}_{\mathrm{d}}\right)$; and one-dimensional PH model (PH1D).

The computational study was based on the partial oxidation of methanol to formaldehyde, which takes place in a fixed bed reactor with a less catalytic active zone at the entrance, obtained with the dilution of the catalyst with inert packing, followed by a zone with only catalyst particles.

The comparison between the predictions of the different types of models showed a good qualitative agreement particularly for the range of the operating conditions tested.

The computation time, on a SUN SPARC 10/52 computer, of the sensitivity coefficients is $3-4 \mathrm{~s}$ for the PH1D model, 4-5 min for the HT1D models and 30-35 min for the HT2D models. This means that when the complexity of the model increases, the difficulty to find out the sensitivity coefficients could increase sharply.

The sensitivity analysis showed that the sensitivity functions usually have a maximum and/or a minimum, which are located in the zone of the hot spot. In general, at the exit of the reactor, the sensitivity coefficients are very low (near zero). The most influent parameter in all the state variables is the wall temperature, so in the design of the reactor this operating condition has to be chosen carefully. For the operating conditions that were tested, the side reaction has a small influence on the reactor behaviour.

The parameters that distinguish the PH models and the HT models related with the interparticle resistances have a small influence on the state variables. Moreover, the intraparticle convection phenomenon leads to an increase in the sensitivity of the system.

The simulation of the two-dimensional models showed that the sensitivity of the state variables are generally higher in the reactor axis, and the most important parameters are the wall temperature, the radial heat Peclet number, the Biot number and the geometrical parameter $\alpha^{\prime}$. The radial mass Peclet number has a lower influence on the state variables.

\section{Greek symbols}

$\alpha^{\prime} \quad$ Geometrical parameter $\left[L^{2} / R_{\mathrm{t}}^{2}\right]$

$\alpha_{i, j} \quad$ Stoichiometric coefficient of component $i$, in reaction $j$

$\Delta H \quad$ Reaction heat, $(\mathrm{J} / \mathrm{mol})$

$\varepsilon_{\mathrm{b}} \quad$ Bed porosity

$\varepsilon_{\mathrm{p}} \quad$ Particle porosity

$\phi_{i} \quad$ Model input parameter

$\phi_{i, \mathrm{o}} \quad$ Thiele modulus referred to the inlet conditions, $\left[R_{p} \sqrt{\rho_{p} R_{l, o} / D_{e, i} C_{M, o}}\right]$

$\eta_{j} \quad$ Effectiveness factor referred to the reaction $j$

$\lambda_{\mathrm{er}} \quad$ Radial effective thermal conductivity ( $/ \mathrm{m} \mathrm{s} \mathrm{K}$ )

$\lambda_{\mathrm{m}, i} \quad$ Mass intraparticle Peclet number of component $i,\left[v_{\mathrm{o}} R_{\mathrm{p}} / D_{\mathrm{e}, i}\right]$

$\theta \quad$ Dimensionless temperature, $\left[T / T_{\mathrm{o}}\right]$

$\theta_{\mathrm{bo}} \quad$ Dimensionless feed temperature, $\left[T_{\mathrm{b}, \mathrm{o}} / T_{\mathrm{o}}\right]$

$\theta_{\mathrm{s}}{ }^{*} \quad$ Dimensionless catalyst temperature at the hot spot conditions, $\left[T_{\mathrm{s}, \max } / T_{\mathrm{o}}\right]$

$\theta_{\mathrm{w}} \quad$ Dimensionless wall temperature, $\left[T_{\mathrm{w}} / T_{\mathrm{o}}\right]$

$\rho \quad$ Density $\left(\mathrm{kg} / \mathrm{m}^{3}\right)$ 
Subscripts

b

d

dc

$\mathrm{F}$

$i$

j

$\mathrm{M}$

$\mathrm{O}$

$\mathrm{p}$

S

W

\section{Superscripts}

\section{Notation}

$A_{\mathrm{p}} \quad$ Specific particle area $\left(\mathrm{m}^{-1}\right)$

$a_{\mathrm{v}} \quad$ Specific particle area (referred to the reactor volume), $\left[a_{\mathrm{v}}=\left(1-\varepsilon_{\mathrm{b}}\right) A_{\mathrm{p}}\right]\left(\mathrm{m}^{-1}\right)$

$B i_{\mathrm{w}} \quad$ Wall heat Biot number, $\left[h_{\mathrm{w}} R_{\mathrm{t}} / \lambda_{\mathrm{er}}\right]$

$B_{j} \quad$ Adiabatic temperature rise for reaction $j$. $\left[(-\Delta H)_{j} C_{\mathrm{M}, \mathrm{o}} / \rho_{\mathrm{f}} C p_{\mathrm{f}} T_{\mathrm{o}}\right]$

$C_{i, \mathrm{~b}} \quad$ Concentration of component $i$ at the bulk $\left(\mathrm{mol} / \mathrm{m}^{3}\right)$

$C_{i, \text { bo }} \quad$ Concentration of component $i$ in the feed $\left(\mathrm{mol} / \mathrm{m}^{3}\right)$

$C_{\mathrm{M}, \mathrm{o}} \quad$ Feed methanol concentration $\left(\mathrm{mol} / \mathrm{m}^{3}\right)$

$C p_{\mathrm{f}} \quad$ Heat capacity of the fluid $(\mathrm{J} / \mathrm{kg} \mathrm{K})$

$D a \quad$ Damköhler number, $\left[L \rho_{\mathrm{b}} R_{1, \mathrm{o}} / u_{\mathrm{o}} C_{\mathrm{M}, \mathrm{o}}\right]$

$D_{\mathrm{e}, i} \quad$ Effective diffusivity for component $i$ in the catalyst $\left(\mathrm{m}^{2} / \mathrm{s}\right)$

$D_{\text {er }} \quad$ Effective radial diffusivity $\left(\mathrm{m}^{2} / \mathrm{s}\right)$

$d_{\mathrm{pe}} \quad$ Equivalent diameter of the particle (volume/ area) (m)

$d_{\mathrm{t}} \quad$ Diameter of the reactor tube (m)

$\boldsymbol{E} \quad n \times n$ matrix of constant coefficients

$f_{i, \mathrm{~b}} \quad$ Dimensionless concentration of component $i$ in the bulk, $\left[C_{i, \mathrm{~b}} / C_{\mathrm{M}, \mathrm{o}}\right]$

$f_{i, \mathrm{p}} \quad$ Dimensionless concentration of component $i$ in the particle, $\left[C_{i, \mathrm{p}} / C_{\mathrm{M}, \mathrm{o}}\right]$

$f_{i, \mathrm{~s}} \quad$ Dimensionless concentration of component $i$ at the catalyst surface, $\left[C_{i, s} / C_{\mathrm{M}, \mathrm{o}}\right]$

$f_{\mathrm{M}, \mathrm{o}} \quad$ Dimensionless concentration of the methanol at the inlet conditions, $\left[C_{\mathrm{M}, \mathrm{o}} / C_{\mathrm{M}, \mathrm{o}}\right]$

$h_{\mathrm{f}} \quad$ Film heat transfer coefficient $\left(\mathrm{J} / \mathrm{m}^{2} \mathrm{~s} \mathrm{~K}\right)$

$h_{\mathrm{w}} \quad$ Wall heat transfer coefficient $\left(\mathrm{J} / \mathrm{m}^{2} \mathrm{~s} \mathrm{~K}\right)$

$k_{\mathrm{f}, i} \quad$ Film mass transfer coefficient for component $i$ $(\mathrm{m} / \mathrm{s})$

$L \quad$ Reactor length (m)
$N f_{\mathrm{h}} \quad$ Number of film heat transfer units, $\left[h_{\mathrm{f}} a_{\mathrm{v}} L /\right.$ $\left.u_{\mathrm{o}} \rho_{\mathrm{f}} C p_{\mathrm{f}}\right]$

$N f_{i} \quad$ Number of film mass transfer units, $\left[k_{\mathrm{f}, i} a_{\mathrm{v}} L / u_{\mathrm{o}}\right]$

$N_{\mathrm{w}} \quad$ Number of wall heat transfer units, $\left[4 U L / d_{\mathrm{t}} \rho_{\mathrm{f}} C p_{\mathrm{f}}\right.$ $\left.u_{\mathrm{o}}\right]$

$P e_{\text {hr }} \quad$ Radial heat Peclet number, $\left[L u_{\mathrm{o}} \rho_{\mathrm{f}} C p_{\mathrm{f}} / \lambda_{\mathrm{er}}\right]$

$P e_{\mathrm{hr}}\left(d_{\mathrm{pe}}\right)$ Radial heat Peclet number based on particle diameter $\left[d_{\mathrm{pe}} u_{\mathrm{o}} \rho_{\mathrm{f}} C p_{\mathrm{f}} / \lambda_{\mathrm{er}}\right]$

$P e_{\mathrm{mr}} \quad$ Radial mass Peclet number, $\left[L u_{\mathrm{o}} / D_{\mathrm{er}}\right]$

$P e_{\mathrm{mr}}\left(d_{\mathrm{pe}}\right)$ Radial mass Peclet number based on particle diameter $\left[d_{\mathrm{pe}} u_{\mathrm{o}} / D_{\mathrm{er}}\right]$

$\operatorname{Re}_{j}^{\mathrm{p}} \quad$ Dimensionless reaction rate $j$, inside the catalyst, $\left[R_{j}^{\mathrm{P}} / R_{1, \mathrm{o}}\right]$

$\operatorname{Re}_{1}^{\mathrm{s}} \quad$ Dimensionless reaction rate $j$, at the surface catalyst conditions, $\left[R_{j}^{\mathrm{S}} / R_{1}, \mathrm{o}\right]$

$R_{1, \mathrm{o}} \quad$ Main reaction rate at feed conditions ( $\mathrm{mol} / \mathrm{kg} \mathrm{s}$ )

$R_{j}^{\mathrm{p}} \quad$ Rate of reaction $j$ inside the catalyst (mol/s kg cat $)$

$R_{j}^{\mathrm{S}} \quad$ Rate of reaction $j$ at the surface catalyst conditions, $\mathrm{mol} / \mathrm{s} \mathrm{kg}_{\text {cat }}$ )

$R_{\mathrm{p}} \quad$ Half thickness of the slab catalyst (m)

$R_{\mathrm{t}} \quad$ Reactor radius (m)

$r^{*} \quad$ Dimensionless reactor radial coordinate, $\left[r / R_{\mathrm{t}}\right]$

$r_{\mathrm{p}_{*}} \quad$ Particle coordinate (m)

$r_{\mathrm{p}}{ }^{*} \quad$ Dimensionless particle coordinate, $\left[r_{\mathrm{p}} / 2 R_{\mathrm{p}}\right]$

$S\left(u_{k} ; \phi_{i}\right)$ Normalised sensitivity of $u_{k}$ with respect to $\phi_{i}$ $\left(=\phi_{i} / u_{k}\left(\partial u_{k} / \partial \phi_{i}\right)\right)$

$\boldsymbol{S}\left(\theta_{\mathrm{s}}{ }^{*} ; \phi_{i}\right)$ Normalised sensitivity of $\phi_{\mathrm{s}}{ }^{*}$ with respect to $\phi_{i}$ $\left(=\phi_{i} / \theta_{\mathrm{s}}^{*}\left(\partial \theta_{\mathrm{s}}^{*} / \partial \phi_{i}\right)\right)$

$s\left(\theta_{\mathrm{s}}{ }_{\mathrm{s}} ; \phi_{i}\right) \quad$ Non-normalised sensitivity of $\theta_{\mathrm{s}}{ }^{*}$ with respect to $\phi_{i}\left(\partial \theta_{\mathrm{s}}{ }^{*} / \partial_{i}\right)$

$T_{\mathrm{b}, \mathrm{o}} \quad$ Feed temperature (K)

$T_{\mathrm{s}, \max } \quad$ Maximum catalyst temperature (K)

$T_{\mathrm{s}, \mathrm{mr}} \quad$ Radial mean temperature in the solid phase $(\mathrm{K})$

$T_{\mathrm{o}} \quad$ Feed temperature (K)

$U \quad$ Overall heat transfer coefficient $\left(\mathrm{J} / \mathrm{m}^{2} \mathrm{~s} \mathrm{~K}\right)$

$u \quad$ Superficial velocity $(\mathrm{m} / \mathrm{s})$

$\boldsymbol{u} \quad$ Vector of the state variables

$u^{*} \quad$ Dimensionless superficial velocity, $\left[u / u_{\mathrm{o}}\right]$

$u_{k} \quad$ State variable

$u_{k, \mathrm{o}} \quad$ State variable at the inlet conditions

$u_{\mathrm{o}} \quad$ Superficial velocity at the inlet conditions $(\mathrm{m} / \mathrm{s})$

$u_{\mathrm{o}} \quad$ Initial conditions of the state variables

$v_{\mathrm{o}} \quad$ Intraparticle fluid velocity $(\mathrm{m} / \mathrm{s})$

$\boldsymbol{W} \quad$ Sensitivity matrix, $\left[\partial \boldsymbol{u} / \partial \phi_{i}\right]$

$z \quad$ Reactor axial coordinate $(\mathrm{m})$

$z^{*} \quad$ Dimensionless reactor axial coordinate, $[z / L]$

\section{References}

[1] S. Feyo de Azevedo, M. Romero-Ogawa, A.P. Wardle, Modelling of tubular fixed-bed catalytic reactors: a brief review, Trans. IChemE 68A (1990) 483-502.

[2] S. Pereira Duarte, G.F. Barreto, N. Lemcoff, Comparison of twodimensional models for fixed bed catalytic reactors, Chem. Eng. Sci. 39 (1984) 1017-1024. 
[3] S. Pereira Duarte, O.A. Ferretti, N. Lemcoff, A heterogeneous onedimensional model for non-adiabatic fixed bed catalytic reactors, Chem. Eng. Sci. 39 (1984) 1025-1031.

[4] Rosendall and Finlayson, Transport effects in packed-bed oxidation reactors, Comp. Chem. Eng. 19(11) (1995) 1207-1218.

[5] O.M. Martinez, S.I. Pereira Duarte, N.O. Lemcoff, Modeling of fixed bed catalytic reactors, Comp. Chem. Eng. 95 (1985) 535-545.

[6] J.N. Papageorgiou, G.F. Froment, Simulation models accounting for radial voidage profiles in fixed-bed reactors, Chem. Eng. Sci. 50 (1995) 3043-3056

[7] G.F. Froment, Fixed bed catalytic reactors technological and fundamental design aspects, Chemie-Ing. Techn. 469 (1974) 374-386.

[8] Pirkle, J.C., Wachs, I.E., Activity profiling in catalytic reactors, Chem. Eng. Prog. (1987).

[9] M. Taniewski, A. Lachowicz, K. Skutil, D. Czechowicz, The effect of dilution of the catalyst bed on its heat-transfer characteristics in oxidative coupling of methane, Chem. Eng. Sci. 5118 (1996) 42714278.

[10] O.A, Sofekun, D.K. Rollins, L.K. Doraiswamy, A random particle model for catalyst dilution, Chem. Eng. Sci. 4916 (1994) 2611-2620.

[11] S. Melis, A. Varma, C.J. Pereira, Optimal distribution of catalyst for a case involving heterogeneous and homogeneous reactions, Chem. Eng. Sci. 52 (1997) 165-169.

[12] A. Nir, L. Pismen, Simultaneous intraparticle forced convection, diffusion and reaction in a porous catalyst-I, Chem. Eng. Sci. 32 (1977) 35-41.

[13] A.E. Rodrigues, J. Loureiro, R.M. Quinta Ferreira, Intraparticle convection revisited, Chem. Eng. Commun. 107 (1991) 21-23.

[14] R.M. Quinta Ferreira, A.C. Costa, A.E. Rodrigues, Effect of intraparticle convection on the transient behavior of fixed-bed reactors: finite differences and collocation methods for solving unidimensional models, Comp. Chem. Eng. 2010 (1996) 1201-1225.

[15] S. Ungureanu, C. Petrila, A. Mares, H. Rabitz, Elementary sensitivity of a chemical reactor described by a quasihomogeneous bidimensional model, Chem. Eng. Sci. 497 (1994) 1015-1024.

[16] Caracotsios, M., Model Parametric Sensitivity Analysis and Nonlinear Parameter Estimation Theory and Applications, Ph.D, University of Wisconsin-Madison, USA, 1986.

[17] J.R. Leis, S.A. Gallagher, M.A. Kramer, Parametric sensitivity analysis of complex process flowsheets using sequential modular simulation, Comp. Chem. Eng. 114 (1987) 409-421.

[18] R.W. Atherton, R.B. Schainker, E.R. Ducot, On the statistical sensitivity analysis of models for chemical kinetics, AIChE J. 213 (1975) 441-448.
[19] M. Demiralp, H. Rabitz, Chemical kinetic functional sensitivity analysis: derived sensitivities and general applications, J. Chem. Phys. 754 (1981) 1810-1819.

[20] R. Yetter, L.A. Eslava, F.L. Dryer, H. Rabitz, Elementary and derived sensitivity information in chemical kinetics, J. Phys. Chem. 888 (1984) 1497-1507.

[21] C. Kiparissides, H. Mavridis, Mathematical modelling and sensitivity analysis of high pressure polyethylene reactors, Nato ASI Series $n^{\circ} 110$ (1986) 759-777.

[22] P. Seferlis, A.N. Hrymak, Sensitivity analysis for chemical process optimization, Comp. Chem. Eng. 2010 (1996) 1177-1200.

[23] H. Rabitz, M. Kramer, D. Dacol, Sensitivity analysis in chemical kinetics, Ann. Rev. Phys. Chem. 34 (1983) 419-461.

[24] M. Dente, A. Collina, I. Pasquon, Verifica di un Reattore Tubolare per la Ossidazione del Metanolo a Formaldeide, La Chimica e L'Industria 486 (1966) 581-588.

[25] P. Jíru, J. Tichý, B. Wichterlová, Kinetik der Oxidation des Methylalkohols zu Formaldehyd an einem Oxidkatalysator, Collection Czechoslov. Chem. Commun. 31 (1966) 674-688.

[26] E. Santacesaria, M. Morbidelli, Kinetics of the catalytic oxidation of methanol to formaldehyde, Chem. Eng. Sci. 36 (1981) 909-918.

[27] L. Windes, M. Schwedock, H. Ray, Steady-State and dynamic modelling of a packed bed reactor for the partial oxidation of methanol to formaldehyde I. Model development, Chem. Eng. Comm. 78 (1989) 1-43.

[28] M. Dente, A. Collina, Cinetica dell'ossidazione del metanolo a formaldeide con catalizzatore a base di ossidi di Fe e Mo - Nota III, La Chimica e L'Industria 478 (1965) 821-829.

[29] Froment, F., Bischoff, B., Chemical Reactor Analysis and Design, 2nd ed., Wiley, New York, 1990

[30] A.G. Dixon, D.L. Cresswell, Theoretical prediction of effective heat transfer parameters in packed beds, AIChE J. 254 (1979) 663-676.

[31] M. Caracotsios, W.E. Stewart, Sensitivity analysis of initial value problems with ODEs and algebraic equations, Comp. Chem. Eng. 94 (1985) 359-365

[32] L.R. Petzold, Differential/algebraic equations are not ODEs, Siam J. Sci. Stat. Comput. 3 (1982) 367-385.

[33] J.R. Leis, M.A. Kramer, Sensitivity analysis of systems of differential and algebraic equations, Comp. Chem. Eng. 91 (1985) 93-96.

[34] R. Quinta Ferreira, A.C. Costa, A.E. Rodrigues, Dynamic behavior of fixed-bed reactors with large-pore catalysts: a bidimensional heterogeneous diffusion/convection model, Comp. Chem. Eng. 168 (1992) 721-751. 